Article

\title{
Depression Mechanism of Strontium Ions in Bastnaesite Flotation with Salicylhydroxamic Acid as Collector
}

\author{
Shiming Cao ${ }^{1,2} \mathbb{E}^{\mathbb{D}}$, Yijun Cao ${ }^{2, *}$, Yinfei Liao ${ }^{2}$ and Zilong $\mathrm{Ma}^{2}$ \\ 1 School of Chemical Engineering and Technology, China University of Mining and Technology, \\ Xuzhou 221116, China; ironshark@163.com \\ 2 National Engineering Research Center of Coal Preparation and Purification, China University of Mining and \\ Technology, Xuzhou 221116, China; ruiyin@126.com (Y.L.); cumtmzl@126.com (Z.M.) \\ * Correspondence: caoyj@cumt.edu.cn; Tel.: +86-0516-8359-1116
}

Received: 3 January 2018; Accepted: 5 February 2018; Published: 13 February 2018

\begin{abstract}
Metal ions are widely present in flotation pulp. Metal ions change solution chemistry and mineral surface properties, consequently affecting mineral flotation. In this work, the effect of strontium ions on bastnaesite flotation with salicylhydroxamic acid (SHA) was investigated by microflotation tests, contact angle measurements, zeta-potential measurements, and X-ray photoelectron spectroscopy (XPS) analysis. Microflotation tests confirmed that the addition of strontium ions decreased bastnaesite floatability, compared with that in the absence of strontium ions. Contact angle measurements suggested that the pretreatment of strontium ions decreased SHA adsorption. Zeta potential measurements confirmed that the bastnaesite was depressed by the adsorption of positively charged strontium species, and the lower adsorption capacity of SHA onto the bastnaesite surfaces was obtained after modifying with strontium ions. XPS analysis demonstrated that strontium ions adsorbed onto the bastnaesite surfaces through the interaction between strontium ions and oxygen atoms of surface $\equiv \mathrm{CeOH}^{0}$ groups. This occurrence hindered surface Ce sites which chelated with SHA and therefore, decreased bastnaesite floatability.
\end{abstract}

Keywords: bastnaesite; strontium ions; depression; flotation

\section{Introduction}

The special electron structure of rare earth elements (REE) leads to their unique fluorescent and chemical properties; therefore, REE play an irreplaceable role in many fields [1]. As technology developed, the demand for rare earth elements has increased continuously in recent years, which requires higher recovery efficiency of rare earth ores.

Bastnaesite is the principal source of light rare earth elements, containing the cerium subgroup or lighter rare earth elements [2]. Froth flotation is an effective method for separating bastnaesite from gangue minerals $[1,3]$ and has received increasing attention in recent years. Hydroxamic acid is a widely used collector in bastnaesite flotation [4-7]. Compared with fatty acid collectors, hydroxamic acid collectors have the advantage of better selectivity between bastnaesite and alkaline minerals [8], because the specificity of the hydroxamic acid functional group for rare earth cations is higher than alkaline earth cations [6,9]. The adsorption of hydroxamic acid collectors on bastnaesite surfaces is attributed to chelation with surface REE [10]. Rao studied the octyl hydroximic acid adsorption mechanism on bastnaesite surfaces with FT-IR and XPS measurements; the results showed that there may be only one kind of five-ring member chelate $(-\mathrm{C}=\mathrm{R}-\mathrm{RE}-\mathrm{O}-\mathrm{N}-)$ existing on the surfaces of bastnaesite [11]. The adsorption mechanism of salicylhydroxamic acid (SHA) on bastnaesite surfaces 
was proved to be chemisorption, by Wang et al. [12]. SHA interacts with active cationic sites on bastnaesite surfaces to form a stable five-ring member chelate.

In practical mineral flotation, the pulp contains various metal ions, which are usually referred to as "unavoidable ions". The metal ions inevitably change solution chemistry, mineral surface properties and therefore, affect mineral flotation. The metal ions come from multiple sources, such as mineral dissolution [13-16] and fluid inclusions [17-19]. Bastnaesite and common gangue minerals, such as calcite, fluorite, barite and celestite, are typical semisoluble minerals [20], which are characterized by ionic bonding and limited solubility in water. In addition, metal salts may be used as modifying reagents [21]. Feng et al. [22] investigated the activation mechanism of lead ions in cassiterite flotation with salicylhydroxamic acid as the collector; the results revealed that lead ions adsorbed onto the mineral surfaces through the interaction between lead species and oxygen sites of cassiterite surfaces to form $\mathrm{Sn}-\mathrm{O}-\mathrm{Pb}^{+}$. This phenomenon increased the number of active collector adsorption sites and hence, increased the floatability of cassiterite. Aluminium ions were used as depressants in the selective flotation of bastnaesite from monazite; the depressing effect of potassium alum appeared to be due to the preferential adsorption of hydrolyzed aluminum species on monazite, in comparison to bastnaesite [21]. Ren J found that the depression of monazite is attributed to the preferential adsorption of $\mathrm{Al}^{3+}$ on monazite surface $\mathrm{PO}_{4}^{3-}$ sites [23]. Deng et al. [24] reported that iron ions sharply decreased smithsonite flotation recovery even at a low concentration. The iron ions adsorbed to the mineral surfaces via both chemical and electrostatic interactions. The depression may be attributed to strong oxidation and hydrolysis. Despite these studies, there are still many knowledge limitations with respect to metal ion adsorption mechanism on bastnaesite surfaces and its implications on flotation.

Strontianite and celestite are primary stromtium minerals, and they are important gangue minerals in some rare earth mines. As semisoluble salt minerals, which are characterized by relatively high solubilities, the dissolution behaviors of these minerals have been widely investigated. The implication of strontianite dissolution in an aqueous environment was confirmed by a previous dissolution study [25,26]. Celestite has been proven to be highly reactive at room temperature; dissolution of celestite plays an important role in determining the Sr composition in aqueous solution [27-29]. Therefore, the dissolution of strontium ions into flotation pulp is inevitable. However, minimal information is available in the published literature in regard to the interaction mechanisms involving strontium ions, collectors and bastnaesite surfaces.

In flotation pulp, metal ions are usually adsorbed before the addition of collectors; therefore, it is necessary to consider change in surface potential, atomic compositions and collector adsorption in the presence of strontium ions. In the present work, the influence of strontium ions on bastnaesite flotation with SHA as the collector was exhibited using microflotation experiments, and its mechanism was investigated with contact angle measurements, zeta-potential measurements and XPS analysis.

\section{Materials and Methods}

\subsection{Materials}

The bastnaesite $\left(\mathrm{CeCO}_{3} \mathrm{~F}\right)$ sample used in all the experiments was derived from Zaozhuang, China. The pure bastnaesite sample was enriched by repeated gravity separation and magnetic separation from grinding products of high grade raw ore. Finally, a bastnaesite sample with a purity above $95 \%$ was obtained. The ground products were sieved using a standard screen to achieve a $-74+25 \mu \mathrm{m}$ bastnaesite particle fraction. The rest of the sample was ground continuously until a $-5 \mu \mathrm{m}$ fraction was achieved for zeta-potential measurements.

Strontium chloride hexahydrate $\left(\mathrm{SrCl}_{2} \cdot 6 \mathrm{H}_{2} \mathrm{O}\right)$ was supplied as the strontium ion source, and SHA was employed as the collector. Solution $\mathrm{pH}$ values were regulated using $0.1 \mathrm{~mol} / \mathrm{dm}^{3}$ hydrochloric acid and $0.1 \mathrm{~mol} / \mathrm{dm}^{3}$ sodium hydroxide stock solutions. All reagents employed in the present study were of analytical grade, and pure deionized water was used throughout testing. 


\subsection{Flotation Studies}

Flotation experiments were conducted at room temperature in a small-scale flotation machine, and $2.0 \mathrm{~g}$ of pure bastnaesite samples were added into a $40 \mathrm{~cm}^{3}$ flotation cell. The mineral suspension was first conditioned with $\mathrm{SrCl}_{2}$ stock solution before SHA was added, as necessary. Subsequently, SHA was added and conditioned for $5 \mathrm{~min}$ before the pulp $\mathrm{pH}$ was regulated. After the collected products were filtered and dried, the weight distribution between the floated and unfloated bastnaesite particles was calculated to determine the corresponding recovery.

\subsection{Contact Angle Studies}

The contact angle measurements were conducted using a Drop Shape Analyser (DSA100, KRUSS, Hamburg, Germany) following the pendant droplet method. The samples $(-38 \mu \mathrm{m})$ of untreated bastnaesite, bastnaesite treated with SHA and bastnaesite treated with strontium ions and SHA were prepared by following the same procedure as for single mineral flotation.

\subsection{Zeta-Potential Determination}

The zeta potential of the bastnaesite samples was determined using a ZetaPlus instrument (Brookhaven, New York, NY, USA). The mineral suspension (0.125\% mass fraction) was dispersed and fully vibrated for a desired time by a constant temperature bath oscillator. This step was performed in the presence of desired reagent concentrations at a determined $\mathrm{pH}$. After $30 \mathrm{~min}$ of the resultant suspension settling, the $\mathrm{pH}$ was measured and recorded, and the fine mineral particles were transferred to measure zeta potentials.

\subsection{XPS Analysis}

XPS were conducted for untreated bastnaesite and bastnaesite treated with strontium ions. The interaction products were examined via ESCALAB 250Xi (Thermo Fisher, Waltham, MA, USA) with an Al K Alpha source. A survey scan of the analyzed sample was first conducted to detect elemental compositions, and then a precise scan was performed to obtain the XPS spectrum of a specific element. The C 1s spectrum at $284.8 \mathrm{eV}$ was obtained and used as an internal standard to calibrate all of the measured spectra for charge compensation.

\section{Results and Discussion}

\subsection{Effect of Strontium Ions on Bastnaesite Floatability}

Microflotation tests of bastnaesite treated with SHA in the absence and presence of strontium ions at different $\mathrm{pH}$ were conducted, to examine the effect of strontium ions on the flotation behavior (Figure 1). As the $\mathrm{pH}$ increased, the recovery of bastnaesite increased gradually, reaching a maximum of $72.3 \%$ at approximately $\mathrm{pH}$ 8.0. The bastnaesite floatability dropped sharply at $\mathrm{pH}>9$. In an acidic environment, SHA was mainly present in the form of molecules, which limited SHA adsorption. The ionization of SHA incrementally increased with rising $\mathrm{pH}$, leading to the increase of recovery at $\mathrm{pH}<8$; but in heavy alkaline solution, the competitive adsorption between SHA ions and hydroxyl ions decreased SHA adsorption. Therefore, under acidic and heavy alkaline conditions the bastnaesite obtained poor floatability. In the presence of strontium ions, the recovery decreased over the entire flotation $\mathrm{pH}$ range. At $\mathrm{pH} 8$, the flotation recovery decreased to $45.4 \%$; the gap between the two recovery curves was $26.9 \%$, meaning a notable decrease in bastnaesite recovery. In contrast to the experiments in the absence of strontium ions, maximal recovery was obtained at $\mathrm{pH} 6.5$; this may be attributed to surface modification due to the addition of strontium ions. 


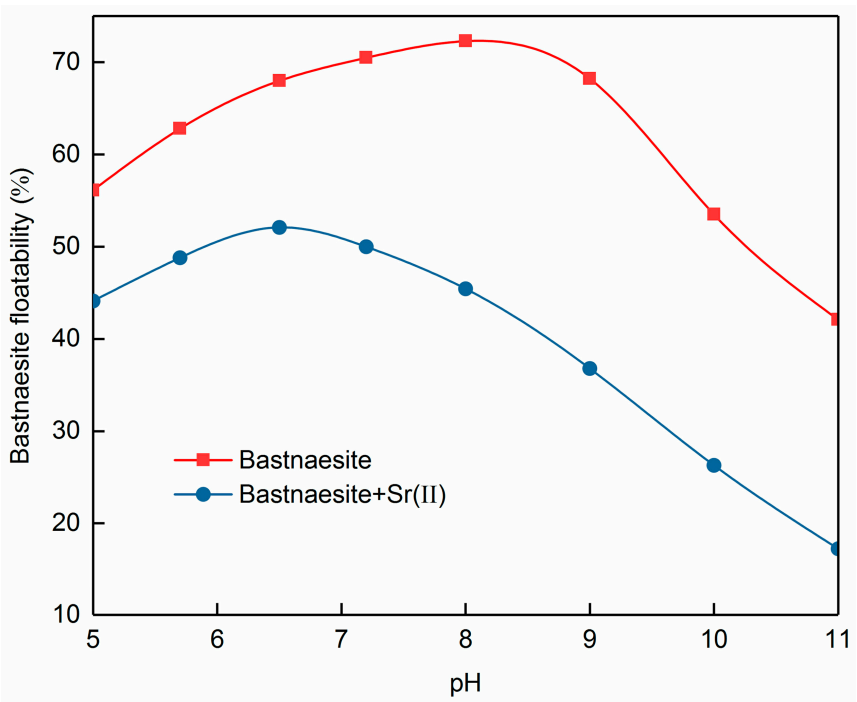

Figure 1. Floatability of bastnaesite with salicylhydroxamic acid (SHA) as the collector, in the absence and presence of strontium ions at different $\mathrm{pH}$ (strontium ions: $1 \times 10^{-4} \mathrm{~mol} / \mathrm{dm}^{3}$, SHA: $5 \times 10^{-4} \mathrm{~mol} / \mathrm{dm}^{3}$ ).

The hydrophobicity of bastnaesite, bastnaesite treated with SHA, and bastnaesite treated with strontium ions and SHA at $\mathrm{pH} 8$ was characterized by contact angle measurements. The results are shown in Figure 2. The contact angle of untreated bastnaesite was $25.5 \pm 0.30^{\circ}$, as shown in Figure 2a, indicating a weak hydrophobicity. After being treated with SHA, the contact angle increased to $42.8 \pm 0.14^{\circ}$ (Figure $2 \mathrm{~b}$ ), meaning SHA could adsorb on bastnaesite surfaces, to increase hydrophobicity. The contact angle of bastnaesite treated with strontium ions and SHA was $38.6 \pm 1.51^{\circ}$, as shown in Figure 2c, indicating that the addition of strontium ions decreased the adsorption of SHA on bastnaesite surfaces.

(a)
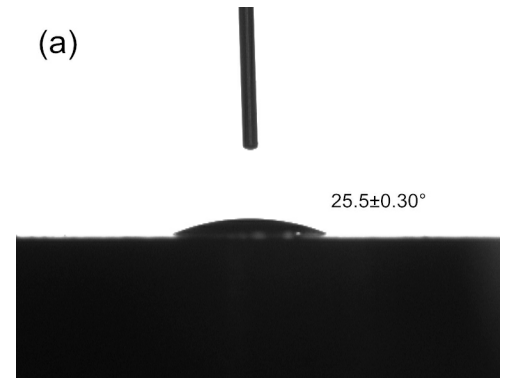

(b)

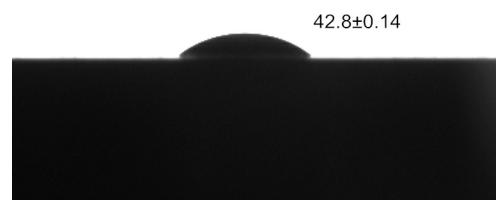

(c)

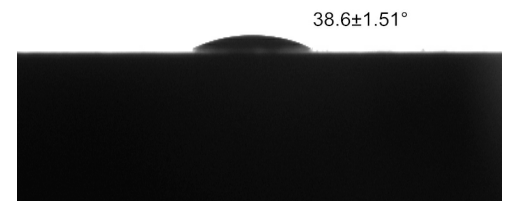

Figure 2. The contact angle images of a water sessile drop on the pressed pellet of (a) bastnaesite; (b) bastnaesite treated with SHA; (c) bastnaesite treated with strontium ions and SHA. ( $\mathrm{pH}=8$, strontium ions: $1 \times 10^{-4} \mathrm{~mol} / \mathrm{dm}^{3}$, SHA: $5 \times 10^{-4} \mathrm{~mol} / \mathrm{dm}^{3}$ ).

The contact angle results show how strontium ions and SHA can change the surface hydrophobicity of bastnaesite surfaces; this is in agreement with the single mineral flotation results, which showed that strontium ions can depress the SHA flotation of bastnaesite. The depression may be attributed to the decrease of SHA adsorption on bastnaesite surfaces. As previously stated, SHA molecules adsorb on bastnaesite surfaces by chelating with surface REE (Ce) sites; after the addition of strontium ions, the number of active REE sites may be decreased and hence, the adsorption of SHA is also decreased.

\subsection{Effect of Strontium Ions on Zeta Potential of Bastnaesite}

Figure 3 shows the zeta potential of the bastnaesite treated and not treated with strontium ions, as a function of $\mathrm{pH}$, in the absence and presence of SHA. As shown in Figure 3, the isoelectronic point 
(IEP) of the untreated bastnaesite was achieved at approximately $\mathrm{pH} 9$. Hence, the bastnaesite surface was positively charged below $\mathrm{pH} 9$ and negatively charged above $\mathrm{pH} 9$. However, the point of zero charge (PZC) of bastnaesite, reported by Ren et al. [6,21] and Zhang [3], is 8.6; the difference may be due to the different bastnaesite samples used. There are two kinds of broken bonds present on the bastnaesite surfaces: $\equiv \mathrm{F}-\mathrm{Ce}^{2+}$ and $\equiv \mathrm{CO}_{3}^{2-}$ [30-32]. Due to surface protonation, these broken bonds convert into $\equiv \mathrm{F}-\mathrm{CeOH}^{0}$ and $\equiv \mathrm{CO}_{3} \mathrm{H}^{0}$ groups in aqueous environment [33,34]. For bastnaesite, $\mathrm{H}^{+}, \mathrm{OH}^{-}$and $\mathrm{CO}_{3}^{2-}$ were found to determine the surface potential $[35,36]$. Therefore, the zeta potential can be influenced primarily by $\mathrm{pH}$.

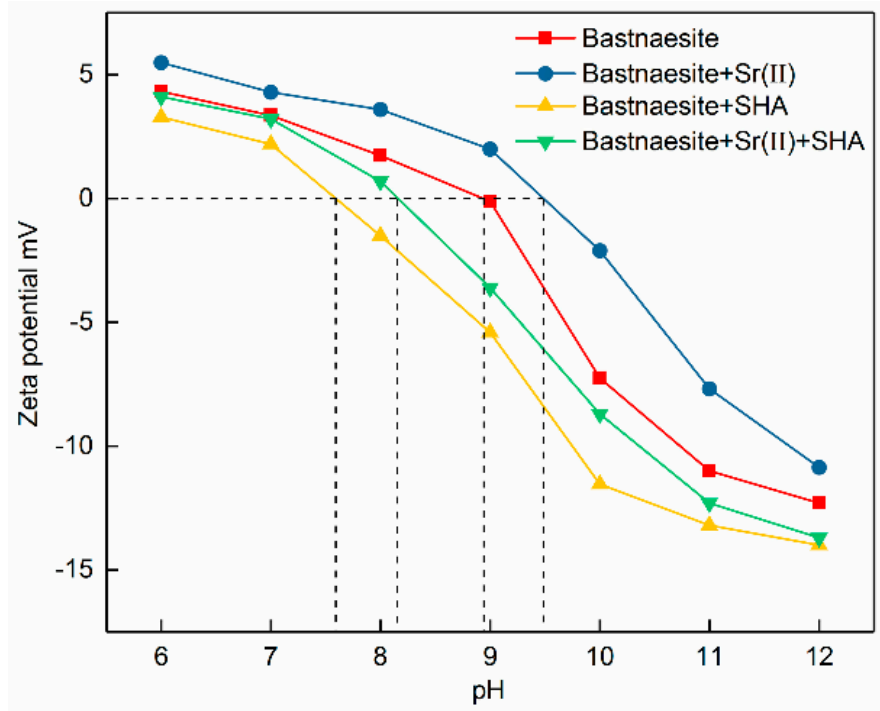

Figure 3. Zeta potential of bastnaesite treated and not treated with strontium ions as a function of $\mathrm{pH}$ in the absence and presence of SHA.

After the mineral surface was treated with strontium ions, the zeta potential of bastnaesite shifted positively across the whole $\mathrm{pH}$ range, and the IEP increased from 9 to 9.5. This result indicates the adsorption of strontium ions on bastnaesite surfaces. The strontium ion species distribution in the solution as a function of $\mathrm{pH}$ was calculated, to reveal the interaction between strontium ions and bastnaesite surfaces.

Figure 4 plots the diagram of strontium ion species distribution as a function of $\mathrm{pH}$ based on solution chemistry calculation [37]. It can be seen that across the entire $\mathrm{pH}$ range, only cationic strontium ion species are present. The hydrolysis of strontium ions in aqueous solution is quite weak; only monohydroxy complexes form at a high $\mathrm{pH}$. At $\mathrm{pH}<10.6$, there are only free $\mathrm{Sr}^{2+}$ ions in solution. The percentage of $\mathrm{SrOH}^{+}$increases rapidly at $\mathrm{pH}>12$.

Figures 3 and 4 signify that the positively charged $\mathrm{Sr}^{2+}$ adsorbed onto the mineral surface with a positive charge at $\mathrm{pH}$ below IEP; the adsorption cannot be attributed to electrostatic attraction. Therefore, the strontium ions may be adsorbed on bastnaesite surfaces due to chemical interaction. At a $\mathrm{pH}$ above IEP, the positively charged $\mathrm{Sr}^{2+}$ and $\mathrm{SrOH}^{+}$may be adsorbed on negatively charged mineral surfaces due to both electrostatic and chemical interactions.

The influence of SHA on the zeta potential of bastnaesite surfaces in the absence and presence of strontium ion pretreatment is also demonstrated in Figure 3. It can be seen that after treating with SHA, the zeta potential decreased, and the IEP reduced, from 9 to 7.6. This is attributed to the chelating of anionic hydroxyl groups in SHA with REE sites of bastnaesite surfaces. As shown in Figure 3, the addition of strontium ions before SHA diminished the influence of SHA on zeta potential. The zeta potential of bastnaesite shifted less negatively relative to that in the absence of strontium ions. Moreover, the IEP only reduced from 9 to 8.1. This may be attributed to the decrease in SHA adsorption when strontium ions are used, and is consistent with the microflotation and contact angle results. 


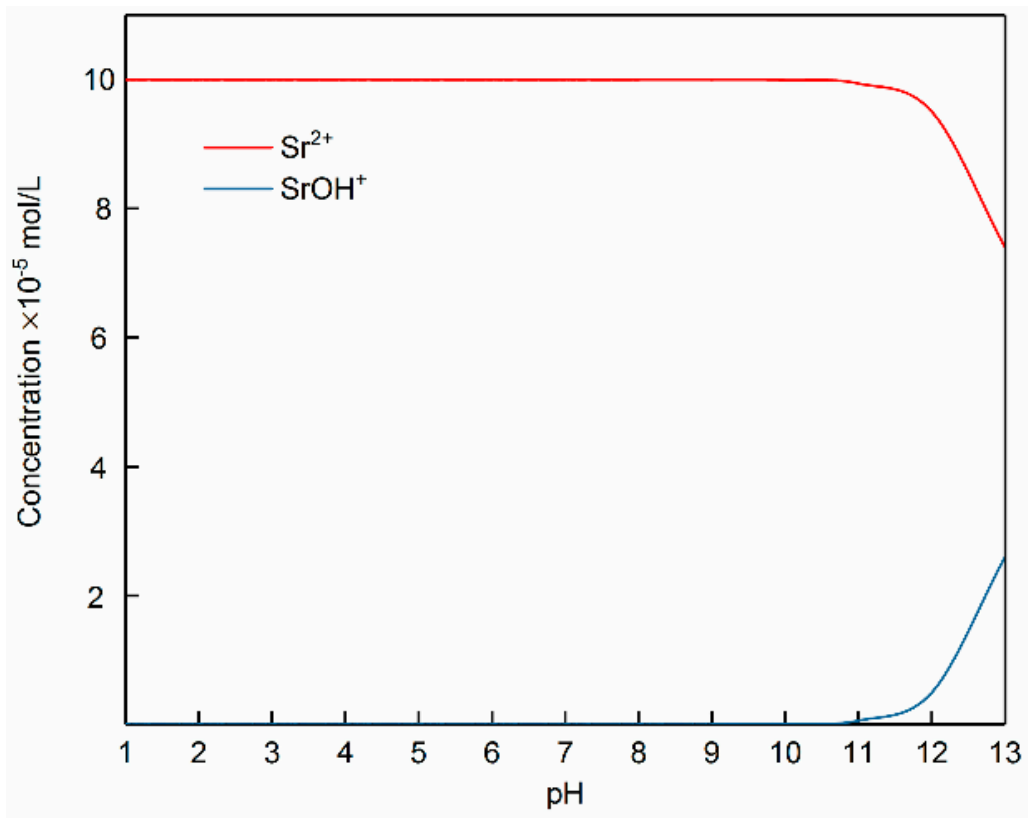

Figure 4. Species distribution diagram of strontium ions as a function of $\mathrm{pH}$. $[\mathrm{Sr}(\mathrm{II})]=1 \times 10^{-4} \mathrm{~mol} / \mathrm{dm}^{3}$.

\subsection{Adsorption Mechanism of Strontium Ions on Bastnaesite Surfaces}

Based on the distinctive binding energies of the inner electrons of each element, XPS was used to identify both the chemical compositions and chemical states of the elements on sample surfaces. In this work, XPS was used to characterize the differences between untreated bastnaesite samples and bastnaesite treated with strontium ions. The resulting spectra were analyzed via peak fitting and separation, and the relative concentrations of various components were determined after using MultiPak Spectrum software to remove the portions of the spectra that represented contamination.

The XPS survey spectra of the original bastnaesite, the bastnaesite treated with strontium ions within a binding energy of $1000.0 \mathrm{eV}$, are shown in Figure 5. It can be seen that in both Figure 5a,b, a Sr signal could not be detected, this may be due to the low adsorption capacity of strontium ions on bastnaesite surfaces. As shown in Figure 6, in the high-resolution XPS spectra for the original bastnaesite, Sr spectra also cannot be detected, suggesting high purity of the bastnaesite samples. However, on the bastnaesite surfaces treated with strontium ions (Figure 6), an Sr 3d peak, positioned at $134.6 \mathrm{eV}$, appeared, indicating the adsorption of strontium ions. Metal ions have been proven to be adsorbed on some carbonate minerals, by complexing with surface $\mathrm{CO}_{3}^{2-}[24,38]$, while the binding energy of $\mathrm{Sr} 3 \mathrm{~d}$ in $\mathrm{SrCO}_{3}$ is $133.2 \mathrm{eV}$ [39], apparently different from that of adsorbed Sr in this work, indicating the strontium ions may not adsorb by complexing with surface $\mathrm{CO}_{3}^{2-}$ of bastnaesite surfaces to form $\mathrm{SrCO}_{3}$.

As shown in Figure $7 \mathrm{a}$, the peak positioned at $684.65 \mathrm{eV}$ is ascribed to $\mathrm{F} 1 \mathrm{~s}$ of bastnaesite surfaces [40]. After treatment with strontium ions, the binding energy of F 1s was still $684.65 \mathrm{eV}$, as shown in Figure 7b, implying that the chemical surroundings of $F$ have not changed. This suggests that the surface F atom was not involved into the chemical adsorption reaction; therefore, it can be deduced that the surface $\mathrm{F}$ atom may not be the chemical adsorption site for strontium ions. 


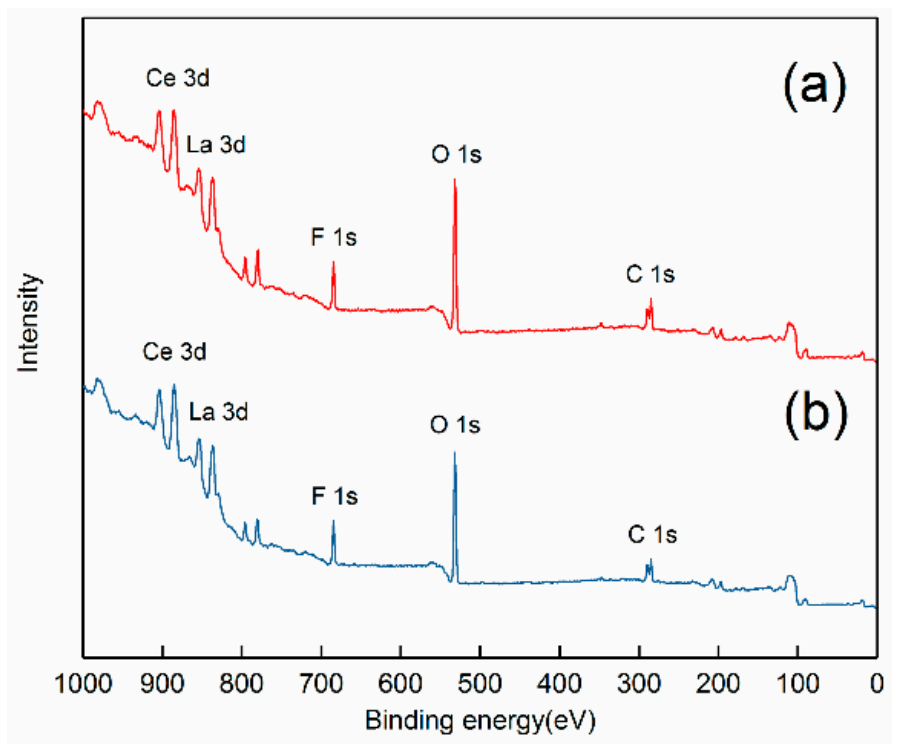

Figure 5. XPS survey spectra of (a) untreated bastnaesite; (b) bastnaesite treated with strontium ions.

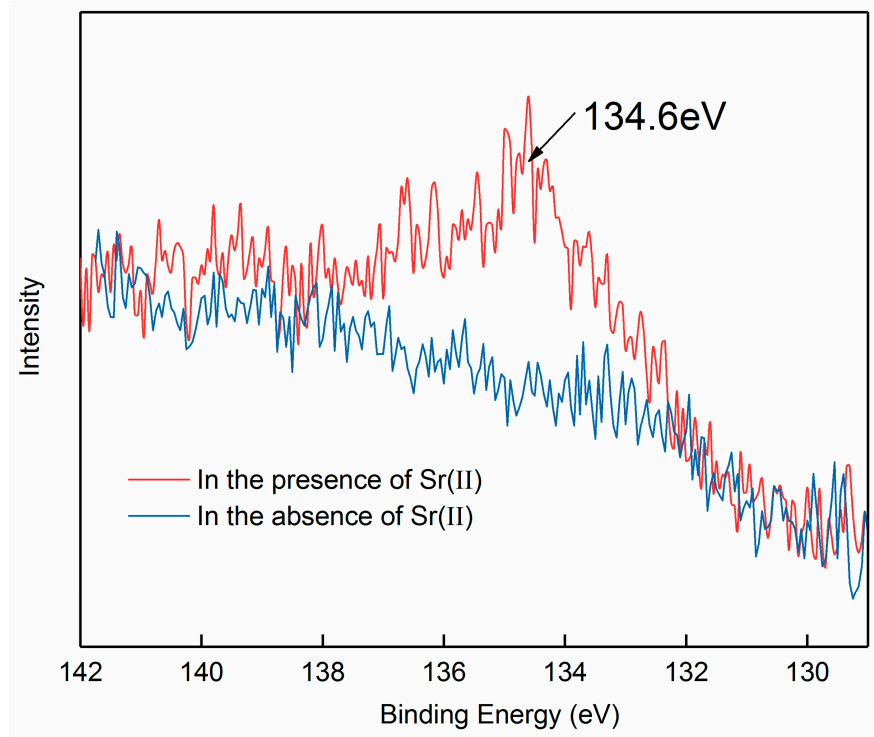

Figure 6. Sr 3d spectra of (a) untreated bastnaesite; (b) bastnaesite treated with strontium ions.
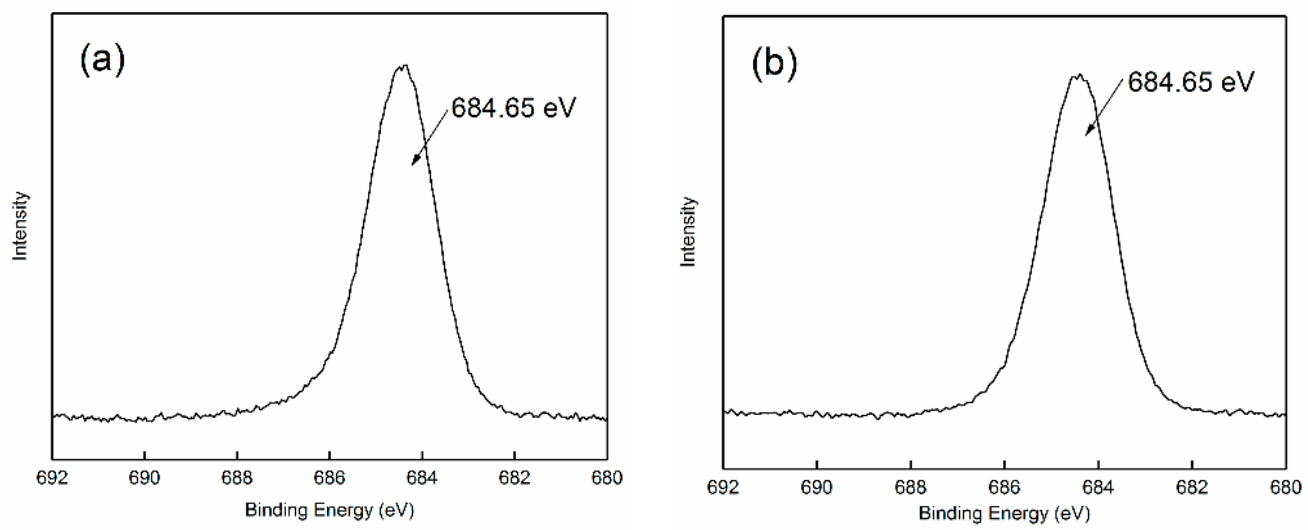

Figure 7. F 1s spectra of (a) untreated bastnaesite; (b) bastnaesite treated with strontium ions. 
The C 1s spectrum in Figure 8a exhibited two well-separated peaks at $284.8 \mathrm{eV}$ and $289.6 \mathrm{eV}$. The components at $284.8 \mathrm{eV}$ were assigned to carbon contamination, while the peak at $289.6 \mathrm{eV}$ was assigned to the $\mathrm{C}$ of $\mathrm{CO}_{3}^{2-}$ in bastnaesite $[40,41]$. As shown in Figure $8 \mathrm{~b}$, after strontium ion adsorption, the binding energy of $\mathrm{C} 1 \mathrm{~s}$ in $\mathrm{CO}_{3}^{2-}$ was $289.65 \mathrm{eV}$; this indicates that the chemical surroundings of the $\mathrm{C}$ atom in the carbonate group had not changed.
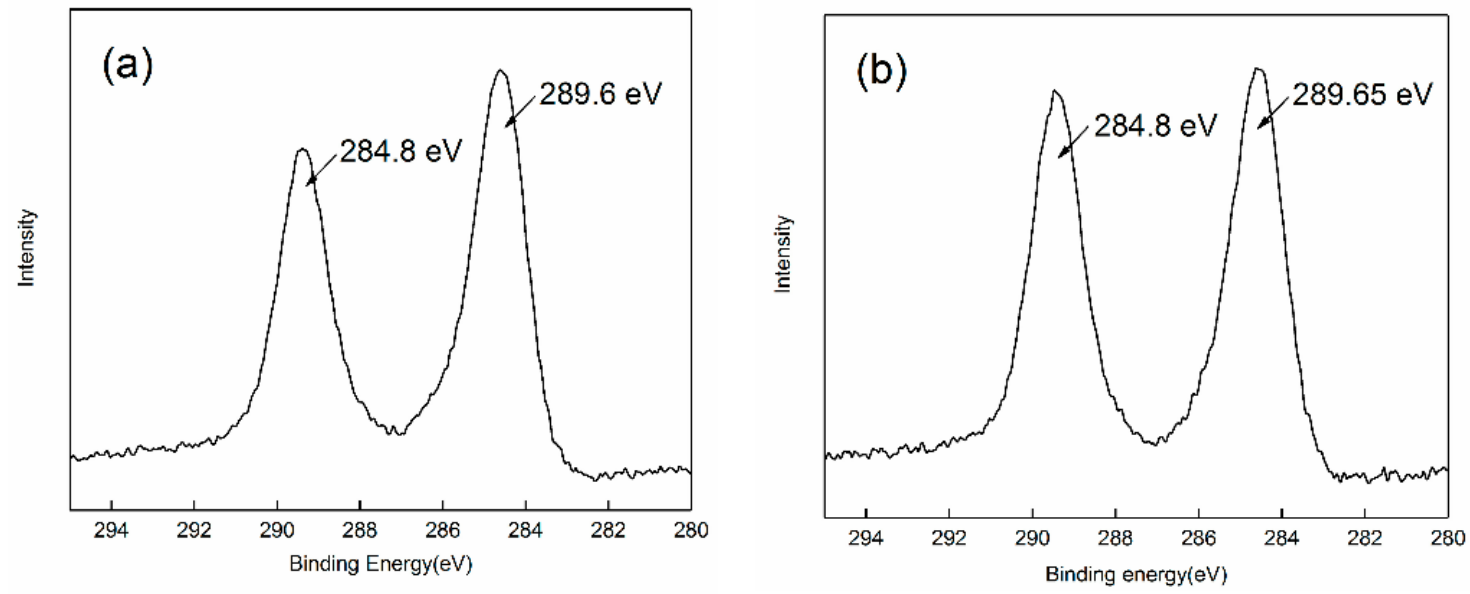

Figure 8. C 1s spectra of (a) untreated bastnaesite; (b) bastnaesite treated with strontium ions.

As shown in Figure 9a, the $\mathrm{O}$ 1s spectrum of the original bastnaesite could be fitted reasonably, with two peaks at $531.57 \mathrm{eV}$ and $532.3 \mathrm{eV}$. The $\mathrm{O} 1$ s peak positioned at $531.57 \mathrm{eV}$ was attributed to the oxygen in carbonate group of bastnaesite [41], and the other peak positioned at $532.3 \mathrm{eV}$ was related to the oxygen in hydroxyl species $\left(\equiv \mathrm{CeOH}^{0}\right)[22,40,42]$. After the bastnaesite surface was modified by strontium ions, the binding energy of $\mathrm{O} 1 \mathrm{~s}$ in the carbonate group barely shifted (Figure 9b), meaning that the chemical surroundings of the $\mathrm{O}$ atom in $\mathrm{CO}_{3}^{2-}$ of bastnaesite have not changed. Combining the $\mathrm{C} 1 \mathrm{~s}$ and $\mathrm{Sr} 3 \mathrm{~d}$ binding energy analyses, it can be concluded that the $=\mathrm{CO}_{3} \mathrm{H}^{0}$ on bastnaesite surfaces is not the adsorption site for strontium ions.

The surface atomic concentrations of $\mathrm{Ce}, \mathrm{C}, \mathrm{O}, \mathrm{F}$ and $\mathrm{Sr}$, determined via XPS, are summarized in Table 1. On the surfaces of untreated bastnaesite, the atomic concentrations of $\mathrm{Ce}, \mathrm{C}, \mathrm{O}$ and F were $6.05 \%, 19.73 \%, 59.66 \%$ and $14.55 \%$, respectively. After strontium ion adsorption, a $\mathrm{Sr} 3 \mathrm{~d}$ signal was detected with a concentration of $0.55 \%$. Compared to the original bastnaesite, the atomic concentration of $\mathrm{C}$ in $\mathrm{CO}_{3}^{2-}$ decreased dramatically, from $19.73 \%$ to $7.97 \%$; this may be attributed to surface $\mathrm{CO}_{3}^{2-}$ dissolution by complexing with $\mathrm{Sr}^{2+}$ in solution to form $\mathrm{SrCO}_{3}(\mathrm{aq})$. The decrease in $\mathrm{C}$ atomic concentration contributed to the increase in $\mathrm{Ce}, \mathrm{O}$ and $\mathrm{F}$ atomic concentrations. Overall, after strontium ion adsorption, the elemental and composition of bastnaesite surfaces were changed and a new $\mathrm{Sr}$ species formed.

Table 1. Atomic concentrations of bastnaesite samples before and after strontium ion treatment.

\begin{tabular}{ccc}
\hline \multirow{2}{*}{ Atom } & \multicolumn{2}{c}{ Atomic Concentration (\%) } \\
\cline { 2 - 3 } & Untreated Bastnaesite & Bastnaesite Treated with Strontium Ions \\
\hline $\mathrm{Ce}$ & 6.05 & 7.98 \\
$\mathrm{C}\left(\right.$ in CO $\left._{3}^{2-}\right)$ & 19.73 & 7.97 \\
$\mathrm{O}$ & 59.66 & 66.25 \\
$\mathrm{~F}$ & 14.55 & 17.25 \\
$\mathrm{Sr}$ & 0 & 0.55 \\
\hline
\end{tabular}


As shown in Figure 9, the binding energy of $\mathrm{O}$ 1s in the hydroxyl species shifted by $-0.42 \mathrm{eV}$ after being treated with strontium ions, meaning that strontium ions may be adsorbed on bastnaesite surfaces by interacting with $\mathrm{O}$ atoms from surface $\equiv \mathrm{CeOH}^{0}$ groups.
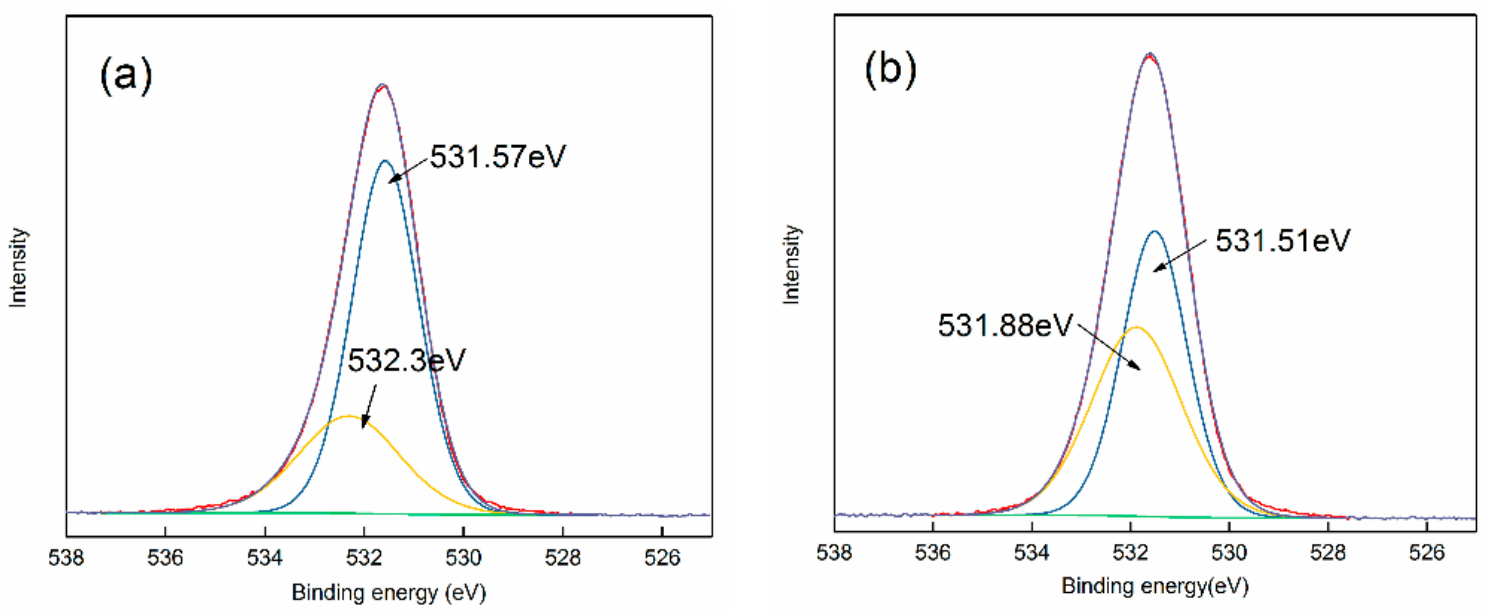

Figure 9. O 1s spectra of (a) untreated bastnaesite; (b) bastnaesite treated with strontium ions.

Figure 10a shows the high-resolution XPS spectra of Ce $3 \mathrm{~d}$ for untreated bastnaesite and bastnaesite treated with strontium ions. The Ce $3 \mathrm{~d}$ of untreated bastnaesite was fitted with a double structure with a binding energy of $904.45 \mathrm{eV}$ for the Ce 3d3/2 level and a binding energy of $885.85 \mathrm{eV}$ for the Ce 3d5/2 level $[41,43,44]$. As shown in Figure 10a,b, after treatment with strontium ions, the binding energy of $\mathrm{Ce} 3 \mathrm{~d} 3 / 2$ shifted significantly by $-0.9 \mathrm{eV}$ and the binding energy of $\mathrm{Ce} 3 \mathrm{~d} 5 / 2$ shifted by $-0.35 \mathrm{eV}$. This result indicates that the chemical surroundings of the Ce atom on bastnaesite surfaces have changed. Combined with the $\mathrm{O} 1 \mathrm{~s}$ binding energy analysis of surface hydroxyl species, it can be concluded that strontium ions adsorbed on bastnaesite surfaces by complexing with oxygen atoms of surface $\equiv \mathrm{CeOH}^{0}$.

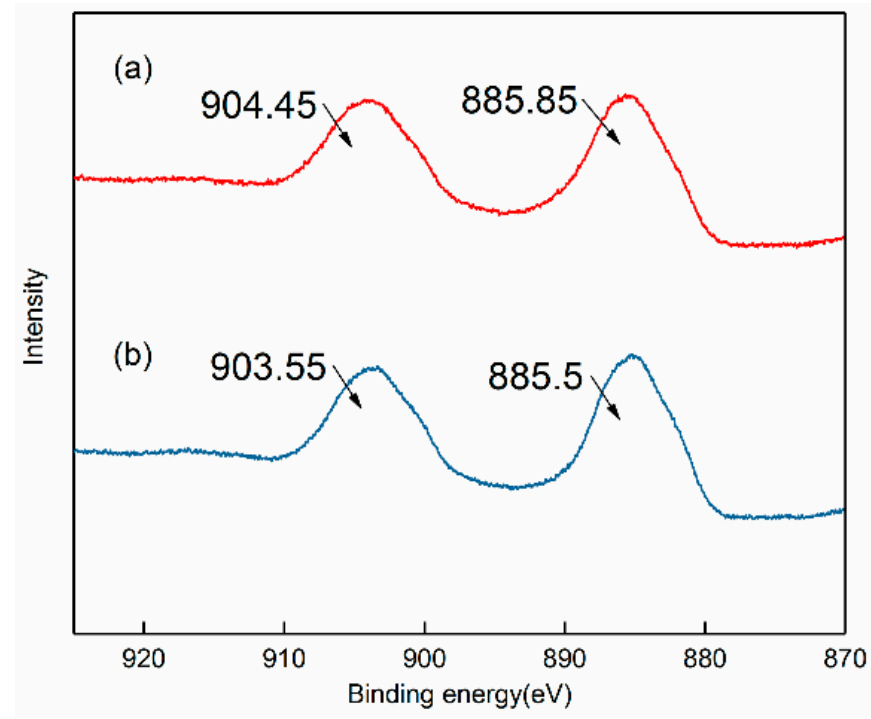

Figure 10. Ce $3 d 3 / 2$ and Ce $3 d 5 / 2$ spectra of (a) untreated bastnaesite; (b) bastnaesite treated with strontium ions. 


\section{Conclusions}

The present work examined the effect of strontium ions on bastnaesite flotation with SHA as the collector. The interaction of strontium ions and SHA with the bastnaesite surfaces was studied by microflotation tests and surface analyses to understand the underlying mechanisms. Given the aforementioned results, the following primary conclusions can be drawn.

The floatability of bastnaesite was decreased by the pretreatment of strontium ions with SHA as the collector, and the recovery of bastnaesite decreased from $72.30 \%$ to $45.44 \%$ at $\mathrm{pH} 8$. Simultaneous contact angles and zeta potential measurements on the bastnaesite surfaces demonstrated that the adsorption of strontium ions decreased SHA adsorption.

The depression mechanism of strontium ions in the bastnaesite flotation might be attributed to the interaction of the strontium species in solution with oxygen atoms from surface $\equiv \mathrm{CeOH}^{0}$ to form the surface complex, $\mathrm{Ce}-\mathrm{O}-\mathrm{Sr}^{+}$. This phenomenon may have hindered the chelation of SHA with surface Ce sites, as shown in Figure 11.

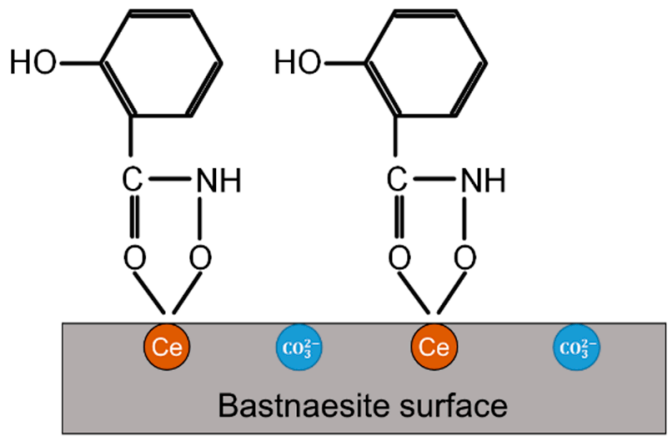

Bastnaesite+SHA

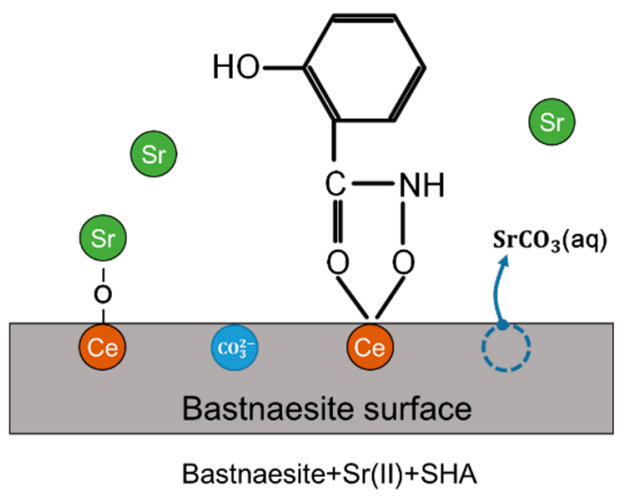

Bastnaesite+Sr(II)+SHA

Figure 11. Schematic representation of depression mechanism of strontium ions in bastnaesite flotation with SHA as collector.

Acknowledgments: This work was supported by National Nature Science Foundation of China (Grant Number 51574240), the National Key Technology R\&D Program for the 12th Five-Year Plan of China (Grant Number 2014BAB01B05) and the Natural Science Foundation of Jiangsu Province (grant number BK20150192).

Author Contributions: Yijun Cao and Shiming Cao designed the experiments; Shiming Cao performed the experiments, analyzed the data and wrote the drafts of the paper; Yinfei Liao and Zilong Ma helped in the preparation of the paper and in checking the drafts of the paper.

Conflicts of Interest: The authors declare no conflict of interest.

\section{References}

1. Chi, R.; Wang, D. Mineral Processing of Rare Earth Minerals; Science Press: Beijing, China, 2014; pp. 33-37.

2. Dolg, M.; Stoll, H. Handbook on the Physics and Chemistry of Rare Earths; Elsevier: Amsterdam, The Netherlands, 1978.

3. Zhang, X. Surface Chemistry Aspects of Fluorite and Bastnaesite Flotation Systems, Doctoral Dissertation; The University of Utah: Salt Lake City, UT, USA, 2014.

4. Liu, W.; Wang, B.; Dai, S.; Ai-Xia, M.A.; Wei, D. Current application and development prospect of hydroximic acid in flotation. Nonferr. Min. Metall. 2006, 22, 25-27.

5. Bulatovic, S.M. Handbook of Flotation Reagents; Elsevier: Amsterdam, The Netherlands, 2007.

6. Ren, J.; Lu, S.; Song, S.; Niu, J. A new collector for rare earth mineral flotation. Miner. Eng. 1997, 10, $1395-1404$. [CrossRef]

7. Fuerstenau, D.W. The adsorption of hydroxamate on semi-soluble minerals. Part I: Adsorption on barite, Calcite and Bastnaesite. Colloids Surf. 1983, 8, 103-119. 
8. Che, L.; Fu, Y.; Pang, J.; Zu, J.; Zhang, F. The application and development of hydroximic acid collector in the flotation of rare earth minerals. Rare Earth 2004, 3, 49-54.

9. Fuerstenau, D.W. Adsorption of hydroxamate collectors on semisoluble minerals. Part II: Effect of temperature on adsorption. Colloids Surf. 1985, 15, 137-146.

10. Zhu, Y.; Zhu, J. Chemical Principles of Flotation Reagents; Central South University of Technology Press: Changsha, China, 1996.

11. Rao, J. The Flotation Behavior Study of Bastnaesite. Master's Thesis, Central South University, Changsha, China, 2013.

12. Wang, C.; Xian, Q.; Hu, Z.; Wang, T.; Li, H. Collecting mechanism of salicylhydroxamic acid on bastnaesite. J. Chin. Soc. Rare Earth 2014, 32, 727-735.

13. Liu, J.; Wen, S.; Xian, Y.; Deng, J.; Huang, Y. Dissolubility and surface properties of a natural sphalerite in aqueous solution. Miner. Metall. Proc. 2012, 29, 113-120.

14. Hu, Y.; Xu, J.; Qiu, G.; Wang, D. Effects of dissolved mineral species on the surface chemical characteristic, electrokinetic property and flotation behavior of fluorite and scheelite. J. Cent. South. Univ. Technol. 1994, 1, 63-67. [CrossRef]

15. Hu, Y. Dissolution/surface property of salt-type minerals and design of schemes of flotation separation. J. Cent. South Inst. Min. Metall. 1992, 23, 273-279.

16. Shin-Nosuke, S.; Tanaka, T.; Yamamoto, K. Crystal structure control of the dissolution of rare earth elements in water-mineral interactions. Geochem. J. 2007, 40, 437-446.

17. Deng, J.; Wen, S.; Xian, Y.; Liu, J.; Bai, S. New discovery of unavoidable ions source in chalcopyrite flotation pulp: Fluid inclusions. Miner. Eng. 2013, 42, 22-28. [CrossRef]

18. Deng, J.; Wen, S.; Liu, J.; Xian, Y.; Wu, D.; Bai, S. New source of unavoidable ions in bornite Flotation Aqueous Solution: Fluid Inclusions. Ind. Eng. Chem. Res. 2013, 52, 4895-4901. [CrossRef]

19. Liu, J.; Wen, S.; Wu, D.; Bai, S.; Liu, D. Determination of the concentrations of calcium and magnesium released from fluid inclusions of sphalerite and quartz. Miner. Eng. 2013, 45, 41-43. [CrossRef]

20. Zhang, X.; Du, H.; Wang, X.; Miller, J.D. Surface chemistry considerations in the flotation of rare-earth and other semisoluble salt minerals. Miner. Metall. Proc. 2013, 30, 24-37.

21. Ren, J.; Song, S. Selective flotation of bastnaesite from monazite in rare earth concentrates using potassium alum as depressant. Int. J. Miner. Process. 2000, 59, 237-245. [CrossRef]

22. Feng, Q.; Zhao, W.; Wen, S.; Cao, Q. Activation mechanism of lead ions in cassiterite flotation with salicylhydroxamic acid as collector. Sep. Purif. Technol. 2017, 178, 193-199. [CrossRef]

23. Ren, J.; Lu, S. The depression mechanism of aluminum salt in the separation of bastnaesite and monazite by flotation. Nonferr. Metal. Eng. 1997, 2, 30-35.

24. Deng, R.; Hu, Y.; Ku, J.; Zuo, W.; Yang, Z. Adsorption of Fe (III) on smithsonite surfaces and implications for flotation. Colloids Surf. A Physicochem. Eng. Asp. 2017, 533, 308-315. [CrossRef]

25. Sonderegger, J.L.; Brower, K.R.; Lefebre, V.G. A preliminary investigation of strontianite dissolution kinetics. Am. J. Sci. 1976, 8, 997-1022. [CrossRef]

26. Mavromatis, V.; Harrison, A.L.; Eisenhauer, A.; Dietzel, M. Strontium isotope fractionation during strontianite $\left(\mathrm{SrCO}_{3}\right)$ dissolution, precipitation and at equilibrium. Geochim. Cosmochim. Acta 2017, 218, 201-214. [CrossRef]

27. Martińez, A.L.; Uribe, A.S. Interfacial properties of celestite and strontianite in aqueous solutions. Miner. Eng. 1995, 8, 1009-1022. [CrossRef]

28. Bose, S.; Hu, X.; Higgins, S.R. Dissolution kinetics and topographic relaxation on celestite (001) surfaces: The effect of solution saturation state studied using Atomic Force Microscopy. Geochim. Cosmochim. Acta 2008, 72, 759-770. [CrossRef]

29. Dove, P.M.; Czank, C.A. Crystal chemical controls on the dissolution kinetics of the isostructural sulfates: Celestite, anglesite, and barite. Geochim. Cosmochim. Acta 1995, 59, 1907-1915. [CrossRef]

30. Donnay, G.; Donnay, J.D. The crystallography of bastnaesite, parisite, roentgenite, and synchisite. Am. Miner. 1953, 38, 932-963.

31. Hsu, L.C. Synthesis and stability of bastnaesites in a part of the system (Ce,La)-F-H-C-O. Mineral. Petrol. 1992, 47, 87-101. [CrossRef]

32. Ni, Y.; Hughes, J.M.; Mariano, A.N. The atomic arrangement of bastnaesite-(Ce), $\mathrm{Ce}\left(\mathrm{CO}_{3}\right) \mathrm{F}$, and structural elements of synchysite-(Ce), roentgenite-(Ce), and parisite-(Ce). Am. Mineral. 1993, 78, 415-418. 
33. Parks, G.A. Surface energy and adsorption at mineral/water interfaces: An introduction. Rev. Mineral. Geochem. 1990, 9, 1-2.

34. Davis, J.A.; Leckie, J.O. Surface ionization and complexation at the oxide/water interface II. Surface properties of amorphous iron oxyhydroxide and adsorption of metal ions. J. Colloid Interf. Sci. 1978, 67, 90-107. [CrossRef]

35. Fuerstenau, D.W. The role of inorganic and organic reagents in the flotation separation of rare-earth ores. Int. J. Miner. Process. 1991, 32, 1-22.

36. Houot, R.; Cuif, J.P.; Mottot, Y.; Samama, J.C. Recovery of rare earth minerals, with emphasis on flotation process. Mater. Sci. Forum 1991, 2, 301-324. [CrossRef]

37. Wang, D.; Hu, Y. Flotation Solution Chemistry; Hunan Science and Technology Press: Changsha, China, 1988.

38. Kobayashi, H.; Satoh, K.; Sawada, K. Adsorption of divalent heavy metal ions on calcium carbonate (calcite). Bunseki Kagaku 2004, 53, 101-107. [CrossRef]

39. Christie, A.B.; Lee, J.; Sutherland, I.; Walls, J.M. An XPS study of ion-induced compositional changes with group II and group IV compounds. Appl. Surf. Sci. 1983, 15, 224-237. [CrossRef]

40. Moulder, J.F.; Chastain, J.; King, R.C.J. Handbook of X-ray photoelectron spectroscopy: A reference book of standard spectra for identification and interpretation of XPS data. Chem. Phys. Lett. 1979, 220, 7-10.

41. Cui, J.; Hope, G.A.; Buckley, A.N. Spectroscopic investigation of the interaction of hydroxamate with bastnaesite (cerium) and rare earth oxides. Miner. Eng. 2012, 5, 91-99. [CrossRef]

42. Nowak, P.; Laajalehto, K.; Kartio, I. A flotation related X-ray photoelectron spectroscopy study of the oxidation of galena surface. Colloids Surface. A Physicochem Eng. Asp. 2000, 161, 447-460. [CrossRef]

43. Kotani, A.; Ogasawara, H. Theory of core-level spectroscopy of rare-earth oxides. J. Electron Spectrosc. Relat. Phenom. 1992, 60, 257-299. [CrossRef]

44. Mullins, D.R.; Overbury, S.H.; Huntley, D.R. Electron spectroscopy of single crystal and polycrystalline cerium oxide surfaces. Surf. Sci. 1998, 409, 307-319. [CrossRef]

(C) 2018 by the authors. Licensee MDPI, Basel, Switzerland. This article is an open access article distributed under the terms and conditions of the Creative Commons Attribution (CC BY) license (http://creativecommons.org/licenses/by/4.0/). 